Shoulder Presentation; T'urning under Influence of Chloroform.

Case 4.-Mrs. C-, a healthy woman of thirty, a dispensary patient, in labour of her fourth child. Her first labour was natural, and the child was born alive. The second pre. sented some anomaly, but she does not know what; the child was also born alive. The third was a cross-birth, and took place eighteen months ago; she was in labour above forty-eight hours, and the two gentlemen who attended her were, she says, thirteen hours in extracting the child, which was dead. She had severe hæmorrhage, and subsequent inflammation of the womb, and was several months before she conld leave her room. This time the labour commenced at about three A.M. The pains soon became severe, and the membranes broke at six. The pains then ceased entirely, and the midwife, detecting an abnormal presentation, sent for me. I arrived at seven, and at once ascertained that the left shoulder was presenting. The pains were then slight, and only occurred at long intervals. The os being sufficiently dilated, $I$ introduced the left hand, without any difficulty, into the uterus, seized a foot, and, after some little resistance, brought it down and turned the child. The pains returned during the turning, and in the course of an hour the body and head of the child were born. The latter passed though the pelvis with so much difficulty that it was evident the pelvic cavity was not a large one, although I conld detect no fault in its diameters with the hand. The child was dead. The cord had prolapsed from the first. The delivery occupied about two hours, and during the entire period the patient was more or less under the influence of chloroform, of which she took about an ounce and a half. I carried its action a little further, previous to and whilst turning, than in the former cases, in order to facilitate the operation as much as possible. The principal circumstance that struck me was, the laxity of the external soft parts and of the vagina; although the patient was rather stout and fleshy, I had no difficulty in introducing the hand. On the whole, I have certainly never before performed the operation of turning, under similar circunstances, with so little difficulty. The placenta soon came away, withont hemorrhage, and I left her comfortable and safe before ten o'clock. She has had no untoward symptom since then, and is now quite convalescent.

In all these cases the soothing, quieting effects produced by the chloroform were most marked; not only at the time it was administered, but for many hours afterwards. In no instance was I obliged to give any opiate subsequently to the confinement, the patient falling into a quiet slumber, and being all but free from after-pains. In these instances, although a considerable quantity of chloroform was inhaled, I did not remark any appreciable morbid symptoms. In the three last, decided therapeutical results were obtained, and in less time, and with less inconvenience to the system, than would have been possible by any other means; indeed, the impression produced on my mind by the attentive study of these cases is so favourable to chloroform, as a most powerful and, when carefully exhibited, safe means of quieting the system, and regulating the action of labour, that I shall not hesitate henceforth to use it even in natural parturition, if the labour is prolonged, and the sufferings of the patient are intense. I quite agree with Dr. Simpson, that extreme and long-continued pain is in itself a great evil, and very often the cause of much subsequent constitutional disturbance. That such is the case, Dr. Simpson triumphantly proved when he recalled the rapidly increasing mortality in parturition as the duration of the labour becomes greater. I have myself seen patients die a few hours after a severe operation, from the shock to the nervous system occasioned by the pain which they endured. One case, more especially, made a deep impression on my mind many years ago. A strong, robust, countrywoman, thirty-four years old, was operated on by M. Velpean, at La Charité, for cancer of the lower extremity of the rectum. The operation was long and painful, lasting above half an hour. No vital organs were wounded, not half a pint of blood was lost, and yet she never rallied, and died in twelve hours.

In the various cases in which $I$ have given chloroform, I have used sometimes a handkerchief, and sometimes a very simple and efficient inhaler made by Mr. Coxeter. Believing, however, that its inhalation is not quite devoid of danger, as I have stated, I have never been anxious to bring the patient at once completely under its influence. When using a handkerchief, I have always chosen a very thin one, easily permeable to the air, and have only made three or four folds at the most. When using the inhaler, I have not left it very long in contact with the mouth, but have allowed the patient occasionally to breathe atmospheric air. The unfortunate fatal case of chloroform-inhalation which has just occurred at Newcastle, appears to me to have probably been owing to the neglect of these precautions in a girl of weak constitution. It is stated, in the report of the inquest, that the chloroform was poured on a tablecloth. If this was really the case, and the tablecloth was kept closely in contact with the mouth and nostrils for the three minutes that occurred before her death, the unhappy termination of the case may be explained. During the three minutes, she would be inhaling the vapour of chloroform only, scarcely if at all diluted with air, which conld but with difficulty pass through the thick texture of a tablecloth, and death was produced, partly by the paralyzing influence of the chloroform, but principally owing to asphyxia caused by the want of oxygen in the lungs. Considered individually, the case is a most lamentable and unfortunate one, but $I$ cannot help thinking that it will prove a useful caution to the profession and the public, showing, as it does, that although an inestimable remedy in the hands of the profession, chloroform is not an agent to be trifled with, or to be trusted to unskilled persons.

I cannot conclude this paper without stating, that the gratitude of the medical profession, and that of the community at large, is due to Dr. Simpson, for the undaunted courage with which he has prosecuted his researches respecting the value of anæesthetic agents in the practice of midwifery, and for the untiring energy and perseverance with which he has laboured to communicate his convictions to his medical brethren. That the use of chloroform in difficult labour will prove the greatest improvement that has ever been made in the obstetric art, to say nothing of its power of diminishing pain, I am firmly convinced, from what I have myself seen, and there can be no doubt but that the name of Dr. Simpson will descend to posterity, in connexion with it, as one of the benefactors of the human race.

Cambridge-square, Hyde-park, February, 1848.

\section{OVARIAN DROPSY TREATED BY PRESSURE.}

By I. B. BROWN, EsQ., M.R.C.S.E.,

constlating-accoucheur to the paddngton lying-in charity, etc.

ON the 15 th of December last, I had the honour of reading before the Westminster Medical Society a paper on "Ovarian Dropsy, and its Treatment by Pressure, \&c.," as advocated by myself in the year 1844, in the pages of THE LANCET. In that paper I detailed the results of all the published cases of success by this treatment, both by myself and others; and $I$ then showed, that in two only had any symptoms of the disease returued, and that, amongst such published cases, not one death had occurred, although the contrary had been asserted by Mr. Stafford Lee, in his work "On Tumours of the Uterus," and repeated by Mr. Cæsar Hawkins and others, on several occasions.* I also attempted (with how much success let others decide) to show that such assertions (the following is a specimen) were totally unfounded in fact. In THE LANCET of May $8 \mathrm{th}, 1847$, in an article headed "Contributions to the Pathology, Diagnosis, and Treatment of Ovarian Tumours," the following passage occurs:-

"If it were alone required to show the insufficiency of the cases adduced by $\mathrm{Mr}$. Brown, a simple reference to the relative dates of their occurrence, and almost sinıultaneous publication, would suffice for their rejection as evidence of the value of his mode of treatment."

I also alluded to certain novel objections, such as, "In no case has the cystic secretion been permanently arrested;" again, "and even if such cases conld be adduced, it would be absurd to regard them as examples of disease cured; the cyst remains, though its secretions be arrested; it still exists, though it be corrugated to its smallest bulk; so long as the sac is present, there is no immunity from disease. For a time, the morbid changes may take place slowly, and insidionsly, but they do occur, and eventually lead to more painful symptoms, and more certain death."

I disproved this novel theory by facts founded on personal experience, and attested by others. I also observed that I had found in some cases that mercury was injurious, and I promised to lay before the profession the results of those cases in which I considered that mercury had proved so, as

* In the discussion which took place at the Westminster Medical Society on Mr. Brown's paper, notwithstanding a most determined opposition to his views by the advocates of extirpation, who also attempted to impugn the success of his treatment, we feel bound to say that Mr. Brown incontestably -REP. LANCET. 
also all those which I had treated unsuccessfully. I now purpose to fulfil my promise, and, in doing so, shall endeavour to point out such facts as strike me to be most important in investigating this serious subject, so that other members of my profession who have already tried, and others who have not yet tried, this mode of treatment, may fully understand its bearings, and fairly try its merits. I trust that every one will state his experience, whether for or against, so that we may really be able to deduce the truth from practical observations, for by such means alone can we find the real value of any mode of treatment recommended for the cure of this, or any other disease.

Case of Miss —, of Queen's-row, Camberwell, aged sixteen

May 10th, 1844.-Having been requested yesterday, by the father of this young lady, to see her, I visited her to-day at eleven o'clock. I found her, although sixteen ycars old, much younger in appearance, with cheerful countenance, the mammæe but little developed. She was a seven months' child, but after a few weeks from her birth she became healthy and lively, and continued a plump, healthy child. Had had measles, scarlatina, hooping-cough, and, in the language of her mother, "recovered from all remarkably well." Has never menstruated, nor suffered from leucorrhœa. I learnt the following facts from the mother:-A year since her daughter felt an uncomfortable pain low down in the right side, but did not much complain till September last, when she, (her mother,) on examination, observed an evident increase of size on that side. This gradually progressed up to January last, when it made more rapid progress, and since March it has very rapidly increased. The pain has not been continuous, but coming on occasionally at intervals of a fortnight, and then lasting only a few days; but at Christmas the pain lasted a month, since which time the swelling has rapidly increased. She is now very indolent, although naturally extremely lively and animated. She prefers the recumbent posture on her back; complains of a tightness round her waist, and a sensation of suffocation; does not otherwise feel ill; passes but little urine, and her bowels are constipated.

At first sight I was at once struck with the evident difference of the two sides of the abdomen, the right being larger than the left. On carefully examining the body, I found the whole cavity filled by a large mass, evidently and distinctly fluctuating, apparently contained in a cyst, which occupied more particularly the right iliac fossa, although passing the median line, and extending into the left, but which could be pushed back towards the right. In the right hypochondriac region there appeared more enlargement (and that of a solid character) than on any other part of the body. This led me to doubt somewhat the nature of the dropsy; still, on the whole, as there was no odema of the extremities, nor wasting of the body generally, I was inclined to consider it a case of encysted ovarian dropsy. The os uteri is perfectly healthy, but lower down than usual. On measuring the body, I found that below the umbilicus she measured thirty-three inches and a half, but above the umbilicus, thirty-four inches and a half, and she stated, from careful observation, that since March, she had increased eight inches, although during that time she had been under medical treatment, the surgeon seriously ad. vising extirpation. As I arranged to meet her medical attendant the next day, I did nothing as to treatment.

May 11th.- Visited her at half-past four P.M., and met her medical attendant, Mr. Howitt, of Walworth, who said that he had visited her for nine weeks, and had at different times carefully examined her, and considered it decidedly ovarian, and that he had requested Dr. Marshall Hall to see her, and he also considered it ovarian. I made a second careful examination, and was perfectly satisfied that it was encysted ovarian dropsy. I could mark the exact boundaries of the cyst. I applied a flannel bandage, eight yards long by six inches broad, tightly round the body, and ordered the following medicine:-Take of blue pill, one drachm; powdered opium, six grains. Make sixteen pills. One night and morning.-Take of sulphate of iron, twenty grains; dilute sulphuric acid, half a drachm; tincture of henbane, two drachms; water to sixteen ounces. An ounce twice a day.Take of blue ointment, half an onnce; compound camphor liniment, half an ounce; olive oil, one ounce. Mix. To be used nisht and morning. To take simple animal diet, with vegetables; no beer or wine. Fixed Tuesday next at four o'clock for my visit.

14 th.- Visited her, and ordered the medicine to be repeated, and made the baudage tighter: the patient fancied she was smaller round the waist. 19th.- Visited my patient, and found her suffering from a little cough. Ordered her linseed-tea, demulcent drinks, and to continue the medicine.

21st.-Cough better, but great irritation at the lower part of the body and over the thighs, from the friction. Took off the flannel bandage and directed it to be lined with linen, and applied tightly again, and to take the following mixture in addition to her pills and ointment:- Take of tincture of squills, one drachm; bicarbonate of potash, one drachm; acetate of potash, five drachms; spirits of juniper, one ounce; water to sixteen ounces. Mix. Three tablespoonfuls twice a day. Mr. Davies visited her, and was struck with the marked difference of the two sides of the abdomen, the right being much more so than the left. He said he could also feel particularly the edge of the cyst on the left side. This confirmed my previous opinion. I measured the abdomen after removing the bandage, and found that below the umbilicus she was exactly thirty-two inches, (instead of thirty -three and a half,) and above the umbilicus, thirty-four, (instead of thirty-four and a half, thus exhibiting an evident decrease. Finding the liniment irritated her skin, I ordered her-Blue ointment and spermaceti, of each one ounce, to make a liniment.

25th.-Visited her again; the medicine had made her sick. Ordered her to take half an ounce for a dose, three times a day. She had voided more urine. Continue friction \&c.

28 th.-Better, excepting that she complains of pain in the right iliac fossa, extending up to the rilus. Continue medicine and mercurial friction.

June 4th.-I found her weak, with loss of appetite. She fancied some ale, which $I$ allowed her.

11th.-Better, more appetite, and the beer seemed to suit her. Measured the abdomen carefully, and found below the umbilicus the measurement was thirty inches and a half, (instead of thirty-two, and above, thirty-three and a half, (instead of thirty-four.) Still to continue the treatment as before.

She continued much the same through the month, except that there was no further decrease. In the first week of July there appeared an increase, and on measuring found she was decidedly larger round the body than a fortnight since. Her appetite and general health not so good; indeed, since her gums became decidedly affected by the mercury, she has not been so well.

July 17 th. - I visited her, and found, on measuring the abdomen, that it was thirty-three inches below, and thirtyfive inches above, the umbilicus. I therefore considered it advisable to tap, as her health was evidently becoming very mueh impaired.

19th.-Mr. Gilson and Mr. Lane saw her with me, and carefully examined her. They agreed with me that she ought to be tapped, as the fluid was pressing severely upon the diaphragm. I placed the patient on the edge of the bed, resting her feet upon a chair. Mr. Lane and Mr. Gilson. passed a broad towel around the abdomen. I introduced a trocar nidway between the pubis and umbilicus into the cyst, and a dark, coffee-coloured, mucilaginous fluid, escaped-thus clearly proving the nature of the disease. The patient was not at all faint, nor did she complain during the operation. On measuring the fluid, we found it to be eighteen pints and a half. Before bandaging the abdomen we carefully examined it, and found in the right hypochondriac region, and partly in the region of the scrobiculus cordis, a hardened tumour, consisting of two parts, a larger one in the right, and a smaller one extending to the left, but distinctly communicating with each other. This appeared to be the liver, and was the same substance that I detected on my first examination, which led me to doubt the nature of the disease; but on pressing above this substance, it gradually descended, and passed into the right iliac fossa-thus clearly demonstrating that it was connected with the cyst, and had been forced up into the region of the liver by the accumulating fluid. On more carefilly examining this tumour, we found the right one indurated and irregular in its surface; but towards the right side of it we could distinctly feel fluid. Not so, however, in the left substance, which appeared entirely made up of a hardened mass. We now applied napkins, doubled up into folds nearly square, and placed them, one over the otiner, on the abdomen, and then applied a flannel bandage tightly over them, stitching the bandage every time it was passed round the body. The patient was then placed in bed, and cxpressed herself as being very comfortable and greatly relieved. In the evening I found her pulse 120, and she complaining of the bandage being tight. Ordered her the following mixture:- Solution of acet. anmonize, one ounce; sweet spirits of nitre, two drachms; camphor mixture, six ounces. A fourth part every six hours. 
20th.-Pnlse 108. I cut the landage entirely through, and placed tapes on each side, and then tied them so as to relieve the pressure a little, and yet have command over the bandage, as mi ht be required. Ordered her a rhubarb draught. She voids her urine much more freely, and more in quantity.

23rd.-Progressed favourably from day to day. I now ordered her the following mixture:-Nitrate of potash, one drachm; acetate of potash, half an ounce; syrup of orangepeel, two drachms; water to eight ounces. An ounce to be taken three times a day.

From this date she gradually increased in size, and the cyst continued to fill fast, her health still improving; but as she now (September 7 th) measures thirty-eight inches, I suggested an operation of extraction by the median section, by Mr. Lane, but her father would not hear of it at present, and earnestly desired to have her tapped. This I did, September 7 th, seven weeks after the last operation, in the presence of Mr. Davies, and drew off twenty pints of a dark albuminous fluid, of a ropy consistency, and towards the end of the operation, many flakes of a more solid matter escaped with some difficulty through the trocar. She bore the operation remarkably well. The other hardened tumours attached to the cyst are evidently increased since the last tapping. I do not expect any good re. sult from my treatment in this case. In ten days the cyst began to fill as fast as before, and I seriously advised the median operation as the only remedy.

I saw nothing of her for some weeks, when I was earnestly requested by her father to see her, and I found she had been under another medical man, who applied the following ointment over the whole surface of the abdomen:-Strong mercurial ointment, mild ditto, of each one ounce; hydriodate of potash, gum camphor, of each two drachms. Mix, to make an ointment. This, spread on lint, was covered over with cotton, over that, oil-silk, and then a bandage; to be kept on for three days, but the agony of the patient would not allow of its application for more than three hours. When I saw her, (a fortnight after this application, ) the whole surface of the abdomen was covered with sloughs, some as large as the palm of my hand, deep-black, and offensive; the patient excessively ex. hausted, rejecting everything from the stomach, having just recovered from a violent diarrhcea. I tried various remedies, but nothing did the least good, and she sank in a few days. I could not obtain a post-mortem.

This case offers two very important practical facts; one, her age, only sixteen, and she had never menstruated, whereas nearly every writer on this subject has asserted, that "no ovarian dropsy existed until the catamenia had appeared." I have always doubted this theory, and expressed my opinion in The Lancet, in the course of the year 1844. Dr. Copland states, that Frank and Itard saw cases as early as the ages of thirteen and fourteen. The other important fact is, that the disease seemed to gain ground more rapidly after the system was fairly under the influence of mercury; and although this case was one of the multilocular form, and closely approaching to a malignant character, still I believe the mercury was injurious. But it is very certain that theimmediate cause of dea th was sloughing of the abdominal parietes, from the application alluded to. I say immediate, because I have no doubt that a few months would have sufficed for the disease itself to terminate her life.

Oxford-square, Hyde-park, 1848.

\section{ILLUSTRATIONS OF THERAPEUTICS.}

\section{By RICHARD LANYON, M.D., LL.D., F.A.S., \&c.} (Continued from page 181.)

\section{Atonic Paraplegia.}

Sept. 8th.- Since the last report, the disease has been stationary; but hypochondriacal symptoms, with which it is frequently connected, are beginniug to show themselves. There is a predisposition to depressed state of the nervous function existing in my patient's family. Her mother, who is, as I before stated, advanced in years, shut herself out from the world, many years ago, by inveterate mental despondency, and some others of her relatives have been disposed to monomania. Under these circumstances, I have enjoined occasional carriage exercise, cheerful conversation, and the reading of amusing works. It is thought also that the less stimulating metallic salts may be advantageously prescribed; she is therefore taking five or six grains of the trisnitrate of bismuth every eight hours.

12th.- The patient is evidently losing ground; the hypochondriacal symptoms are more inveterate, with an almost total loss of voluntary power over the lower limbs; but their insensibility is still unimpaired. There is no complaint whatever about the spine; but she is much distressed by fulness and constriction about the scrobiculus cordis. There is, how. ever, no enlargement, and no pain is afforded on pressure She has full power over the bladder, retains the urine, and discharges it in large quantities without inconvenience, but with considerable intervals. The bowels are not so manageable as heretofore, and the regular circulation is undisturbed. Twelve lecches are ordered to be applied to the pit of the stomach; but I am still of opinion that the real seat of disease is confined, both cause and effect, to the lower extremities. Although the legs are almost useless as far as regards progression, she has but partially lost her influence over them when in a lying position. She is desired to remain in bed, to abandon the use of stimulants generally, but to continue to use the trisnitrate of bismuth as before.

13th.-The leech-bites bled freely for two or three hours, the fulness and constriction about the scrobiculus cordis has disappeared, and the voluntary power has been restored to the lower extremities. The solubility of the bowels is maintained by the occasional use of the compound colocynth extract, in conjunction with the protochlonide of mercury, and the strong liniment of ammonia is still perseveringly rubbed into the enfeebled limbs night and morning. Several years ago, Dr. Parry, of Bath, was led to the same conclusion as Dr. Graves has since arrived at, that paraplegia arises occasionally from affections of other parts of the nervous system, independent of the brain and spinal marrow. He very strikingly remarks, that there are "instances often trnceable either to violent exertion of the lower limbs, or to their exposure to cold, especially when conjoined with moisture." ir This corresponds with the opinion advanced in the former part of this paper, that the exciting cause in the instance under consideration depended on my patient having been exposed for some time to the cold and damp on the green sward. In a valuable communication on the treatment of some muscular affections with purgatives, there is related a case of suspension of the power of locomotion generally, first affecting one leg, then gradually laying under restraint the voluntary muscular apparatus of the body, allowing the patient the freedom only "of turning his head from side to side, and of moving his toes." The symptoms presented to the practitioner led him to trace the cause of the disease to the circumstance, that for some time antecedently "the abdomen had gradually become full and tense, and several days previous to the attack he complained of diarrhoea, at which period he had travelled on the outside of a coach, and caught cold." The indication, then, was, to unload the primæ viæe, and maintain daily the peristaltic action for some time; "and in about three weeks a decided amendment had commenced," and proceeded so uniformly, "that at the end of four months, during which time the purgative system was continued, the dose being varied according to the effects produced, he was enabled to walk about without assistance, and to write." From this period his health was perfectly restored. $\downarrow$ The above passage is a condensation of a report in THE $\mathrm{L}_{\mathrm{ANCET}}$, having points of much practical interest, and which I would recommend the reader to consult. The difference in the treatment demanded, whether the disease be functional or dependent on organio lesion, calls for the nicest discrimination in diagnosis. To return, however, to the consideration of the case under treatment.

15 th.-Disposed as this disease is to be accompanied by irregular action of the bowels, my patient being confined to bed makes it more difficult to preserve their solubility. In other respects she remains in statu quo. I have discovered, from the time my attention was first drawn to this case, an unwillingness to give direct answers, which has invariably made it difficult to obtain an exact knowledge of my patient's actual condition. It was not until this morning, although my efforts have been incessant to detect the exciting and predisposing causes, that I was informed that the patient felt pain on the right side of her head, extending from the ear to the neck, and that she does not see as distinctly as before. There is no congestion about the eyes; but the pupils are preternaturally dilated occasionally. A blister was ordered to be applied to the nape of the neck, to be dressed with the cantharides cerate, and the bowels to be kept in a state of counter-irritation by the ordinary black draught.

23rd.-The blister has been very troublesome, and has discharged copiously; whilst the bowels, although disposed to be sluggish, have been vigorously acted upon. Before this plan was pursued, the patient was removed from bed, merely for

* Parry's Elements of Pathology and Therapeutics, pp. 289, 291. t THE LANCET, vol. i. for $1834-5$, p. 380 